\begin{tabular}{llllllll} 
O P E R A T I O N S R E S E A R C H A N D D E C I S I O N S \\
\hline No. 1
\end{tabular}

DOI: $10.37190 /$ ord210103

\title{
FORECASTING THE CONFIDENCE INTERVAL OF EFFICIENCY IN FUZZY DEA
}

\author{
AZARNOOSH KAFI ${ }^{1}$, BeHROUZ DANESHIAN ${ }^{2 *}$, MOHSEN ROSTAMY-MALKHALIFEH ${ }^{3}$ \\ ${ }^{1}$ Department of Mathematics, Lahijan Branch, Islamic Azad University, Lahijan, Iran \\ ${ }^{2}$ Department of Mathematics, Central Tehran Branch, Islamic Azad University, Tehran, Iran \\ ${ }^{3}$ Department of Mathematics, Science and Research Branch, Islamic Azad University, Tehran, Iran
}

Data envelopment analysis (DEA) is a well-known method that based on inputs and outputs calculates the efficiency of decision-making units (DMUs). Comparing the efficiency and ranking of $D M U$ s in different periods lets the decision-makers prevent any loss in the productivity of units and improve the production planning. Despite the merits of DEA models, they are not able to forecast the efficiency of future periods with known input/output records of the DMUs. With this end in view, this study aims at proposing a forecasting algorithm with a $95 \%$ confidence interval to generate fuzzy data sets for future periods. Moreover, managers' opinions are inserted in the proposed forecasting model. Equipped with the forecasted data sets and concerning the data sets from earlier periods, this model can rightly forecast the efficiency of the future periods. The proposed procedure also employs the simple geometric mean to discriminate between efficient units. Examples from a real case including 20 automobile firms show the applicability of the proposed algorithm.

Keywords: data envelopment analysis (DEA), fuzzy data, efficiency, forecast, ranking, confidence interval

\section{Introduction}

Data envelopment analysis (DEA) is concerned with the comparative assessments of the efficiency of decision-making units (DMUs). In the classical DEA models, the efficiency of a $D M U$ is assessed by maximizing the ratio of the weighted sum of its outputs to the weighted sum of its inputs, provided that this ratio does not exceed 1 for any of the DMUs. Since the pioneering works of Charnes et al. [6] and Banker et al. [2], DEA has demonstrated to be an effective technique for measuring the relative efficiency

*Corresponding author, email address: be_daneshian@yahoo.com Received 14 July 2020, accepted 1 March 2021 
of a set of homogeneous DMUs that utilize the same inputs to produce the same outputs. While the assumption of certain and crisp data is not acceptable in real-world DEA contributions, fuzzy data sets are employed in the efficiency analyses. Moreover, in DEA-related contexts, studies have been conducted in which fuzzy measures have been incorporated.

The concept of fuzzy was first introduced by Zadeh [32, 33]. He also introduced the possibility hypothesis in modelling conditions that face uncertainty. The concept of fuzzy random variables was first used by Kwakernaak et al. $[15,16]$ to represent circumstances in which there are simultaneous fuzzy and coincidental phenomena. Charnes et al. [4] introduced meaningful programming of constraints that establish every constraint at a significant level such as $\alpha$. Land et al. [17] developed a DEA model in this type of programming to calculate the efficiency of units with deterministic inputs and random outputs. Other references that use the fuzzy concept in DEA literature are Olesen and Petersen [23], Kao and Liu [14], Saati et al. [25], and Lertworasirikul et al. [18].

Despite the widespread applicability of DEA, some authors criticize it for a number of its weaknesses. The first drawback relates to the discrimination power of standard DEA models. Standard DEA models divide units into efficient and inefficient units but cannot discriminate between efficient units. Scholarly references to this are Anderson and Peterson [1], Sexton et al. [26], Doyle et al. [7, 8], and Liang et al. [21, 22], all assuming real inputs and outputs in their models. Wang et al. [29] suggested two models for calculating the fuzzy efficiency of units. Among them, Wang ranked the units based on fuzzy arithmetic. Hosseinzadeh et al. [12] and Jahanshahloo et al. [13] considered different aspects in ranking units. Wang and Chin [30] proposed a fuzzy expected value DEA approach with fuzzy inputs and outputs. They first weighted the input/output measures. And then the expected values were used to measure the optimistic and pessimistic efficiencies of $D M U$ s in fuzzy contexts. Finally, the two efficiencies were geometrically averaged for ranking and identifying the best performing $D M U$ s.

The second flaw of standard DEA models relates to the utilization and analyses of previous data. In other words, the DEA standard models fail in forecasting the future and can only evaluate the efficiency concerning earlier data. Various papers focused on this forecasting procedure, employing linear programming and DEA techniques (cf., [34, $11,3,10,31,19,20,9,27,24,28]$ for further discussions on this issue). The main issue in these works is concerned with the ignorance of decision-makers opinions. These works provoked a question in real-world applications of the DEA models which is the concern of the current paper too. It reads as "what would happen if the role of managers were inserted in the forecasting procedure?".

In today's competitive world, managers must think over various factors including the dynamics of the environmental factors, resource consumption, and output production. Moreover, they must rely on information about the due date when the units under review would pass this period. Admittedly, the obtained results, based on the past data, cannot lead to desirable outcomes. Moreover, generalizations of the results do not allow 
the managers to adjust the production activities in terms of resources and production. Hence, managers involve their viewpoints in their evaluations that can seriously affect the final results, meaning that such issues employ managers' opinions as fuzzy value effects.

The main contribution of this paper is its focus on uncertain fuzzy data to introduce managers' viewpoints in the production process. Concerning the historical data along with decision-maker viewpoints, the efficiency of the units can be forecasted with the aid of the proposed model of the current paper.

Another point that was argued in this paper is confidence. To have trustable results, this paper claims a confidence interval of efficiency. A 95\% confidence interval for input/output measures was reached with an alternative algorithm proposed here. Equipped with the manager's arguments and confidence interval of the data sets, the efficiency is forecasted. The expected efficiencies for future periods prompt ranking and discriminating procedure. The paper employs Wang and Chin's [30] fuzzy DEA models to have both pessimistic and benevolent efficiencies. The mean of these efficiencies can rank and compare the units. In the end, a real case of 20 automobile firms utilizing the last 49 periods supports the suggested approach of this paper.

With this end in view, the paper is organized as follows. Section 2 briefly introduces the fuzzy model proposed by Wang and Chin [30]. Section 3 describes the proposed algorithm including the algorithm for forecasting the efficiency confidence interval. A real case including numerical examples is presented in Section 4. Finally, conclusions are provided in Section 5.

\section{Preliminaries. Wang and Chin's (2011) Fuzzy Model}

Fuzzy DEA models are used to calculate the efficiency of $D M U$ s with fuzzy data. Suppose there are $n D M U \mathrm{~s}\left(D M U_{j} ; j=1, \ldots, n\right)$ that use $m$ inputs $\tilde{x}_{i j}=\left(x_{i j}^{L}, x_{i j}^{M}, x_{i j}^{N}, x_{i j}^{U}\right)$ $i=1, \ldots, m$ to produce $s$ outputs $\tilde{y}_{r j}=\left(y_{r j}^{L}, y_{r j}^{M}, y_{r j}^{N}, y_{r j}^{U}\right), r=1, \ldots, s$. The input and output vectors are the inputs and outputs of the trapezoidal fuzzy data where $x_{i j}^{L} \geq 0$ and $y_{r j}^{L} \geq 0$. Wang and Chin [30] define the efficiency of $D M U_{j}, j=1, \ldots, n$ in fuzzy environments as follows:

$$
\theta_{j}=\frac{\sum_{r=1}^{s}\left(u_{r}^{L} y_{r j}^{L}+u_{r}^{M} y_{r j}^{M}+u_{r}^{N} y_{r j}^{N}+u_{r}^{U} y_{r j}^{U}\right)}{\sum_{i=1}^{m}\left(v_{i}^{L} x_{i j}^{L}+v_{i}^{M} x_{i j}^{M}+v_{i}^{N} x_{i j}^{N}+v_{i}^{U} x_{i j}^{U}\right)}, j=1, \ldots, n
$$


where, $\tilde{u}_{r}=\left(u_{r}^{L}, u_{r}^{M}, u_{r}^{N}, u_{r}^{U}\right)$ and $\tilde{v}_{i}=\left(v_{i}^{L}, v_{i}^{M}, v_{i}^{N}, v_{i}^{U}\right)$ are the weights of inputs and outputs, respectively. However, the authors claimed that the efficiency of units can be evaluated as an interval. The upper bound of this interval efficiency is called the optimistic view of evaluation and the lower bound of the interval is called the pessimistic estimate. First, the upper bound of the efficiency is calculated. The efficiency of the lower evaluated unit, that is, can be determined from the optimistic point of $D M U_{o}$ view. The model is called the benevolent model and has the following format:

$$
\begin{aligned}
\max \theta_{o}^{\text {best }}= & \frac{\sum_{r=1}^{s}\left(u_{r}^{L} y_{r o}^{L}+u_{r}^{M} y_{r o}^{M}+u_{r}^{N} y_{r o}^{N}+u_{r}^{U} y_{r o}^{U}\right)}{\sum_{i=1}^{m}\left(v_{i}^{L} x_{i o}^{L}+v_{i}^{M} x_{i o}^{M}+v_{i}^{N} x_{i o}^{N}+v_{i}^{U} x_{i o}^{U}\right)} \\
\text { s.t. } \theta_{j}^{\text {best }}= & \frac{\sum_{r=1}^{s}\left(u_{r}^{L} y_{r j}^{L}+u_{r}^{M} y_{r j}^{M}+u_{r}^{N} y_{r j}^{N}+u_{r}^{U} y_{r j}^{U}\right)}{\sum_{i=1}^{m}\left(v_{i}^{L} x_{i j}^{L}+v_{i}^{M} x_{i j}^{M}+v_{i}^{N} x_{i j}^{N}+v_{i}^{U} x_{i j}^{U}\right)} \leq 1, \quad j=1, \ldots, n \\
& u_{r}^{U} \geq u_{r}^{N} \geq u_{r}^{M} \geq u_{r}^{L} \geq 0, \quad r=1, \ldots, s \\
& v_{i}^{U} \geq v_{i}^{N} \geq v_{i}^{M} \geq u_{i}^{L} \geq 0, \quad i=1, \ldots, m
\end{aligned}
$$

As is seen above, the model is a fractional programming model that measures the best relative performance of $D M U_{o}$. Applying Charnes et al. [5] transformation, the above fractional programming model can be converted into the following linear programming model:

$$
\begin{aligned}
& \max \theta_{o}^{\text {best }}=\sum_{r=1}^{s}\left(u_{r}^{L} y_{r o}^{L}+u_{r}^{M} y_{r o}^{M}+u_{r}^{N} y_{r o}^{N}+u_{r}^{U} y_{r o}^{U}\right) \\
& \text { s.t. } \theta_{o}^{\text {best }} \sum_{i=1}^{m}\left(v_{i}^{L} x_{i o}^{L}+v_{i}^{M} x_{i o}^{M}+v_{i}^{N} x_{i o}^{N}+v_{i}^{U} x_{i o}^{U}\right)=1 \\
& \quad \sum_{r=1}^{s}\left(u_{r}^{L} y_{r j}^{L}+u_{r}^{M} y_{r j}^{M}+u_{r}^{N} y_{r j}^{N}+u_{r}^{U} y_{r j}^{U}\right) \\
& \quad-\sum_{i=1}^{m}\left(v_{i}^{L} x_{i j}^{L}+v_{i}^{M} x_{i j}^{M}+v_{i}^{N} x_{i j}^{N}+v_{i}^{U} x_{i j}^{U}\right) \leq 0, \quad j=1, \ldots, n \\
& { }_{r} \geq u_{r}^{N} \geq u_{r}^{M} \geq u_{r}^{L} \geq 0, \quad r=1, \ldots, s \\
& v_{i}^{U} \geq v_{i}^{N} \geq v_{i}^{M} \geq v_{i}^{L} \geq 0, \quad i=1, \ldots, m
\end{aligned}
$$


As is seen in the model, if the optimal solution of the model (3) is equal to unity, that is $\theta_{o}^{\text {best }}=1, D M U_{o}$ is called an optimistic efficient; otherwise, it is optimistic inefficient. Similar to the benevolent model, the following fractional programming model can evaluate fuzzy data sets from the pessimistic perspective:

$$
\begin{aligned}
\min \theta_{o}^{\text {worst }}= & \frac{\sum_{r=1}^{s}\left(u_{r}^{L} y_{r o}^{L}+u_{r}^{M} y_{r o}^{M}+u_{r}^{N} y_{r o}^{N}+u_{r}^{U} y_{r o}^{U}\right)}{\sum_{i=1}^{m}\left(v_{i}^{L} x_{i o}^{L}+v_{i}^{M} x_{i o}^{M}+v_{i}^{N} x_{i o}^{N}+v_{i}^{U} x_{i o}^{U}\right)} \\
\text { s.t. } \theta_{j}^{\text {worst }}= & \frac{\sum_{r=1}^{s}\left(u_{r}^{L} y_{r j}^{L}+u_{r}^{M} y_{r j}^{M}+u_{r}^{N} y_{r j}^{N}+u_{r}^{U} y_{r j}^{U}\right)}{\sum_{i=1}^{m}\left(v_{i}^{L} x_{i j}^{L}+v_{i}^{M} x_{i j}^{M}+v_{i}^{N} x_{i j}^{N}+v_{i}^{U} x_{i j}^{U}\right)} \geq 1, \quad j=1, \ldots, n \\
& u_{r}^{U} \geq u_{r}^{N} \geq u_{r}^{M} \geq u_{r}^{L} \geq 0, \quad r=1, \ldots, s \\
& v_{i}^{U} \geq v_{i}^{N} \geq v_{i}^{M} \geq v_{i}^{L} \geq 0, \quad i=1, \ldots, m
\end{aligned}
$$

Model (4) is called a pessimistic model that measures the worst performance of $D M U_{o}$ relative to the other $D M U$ s. Charnes et al. [5] transformation converts model (4) to the following linear programming model:

$$
\begin{aligned}
& \min \theta_{o}^{\text {worst }}=\sum_{r=1}^{s}\left(u_{r}^{L} y_{r o}^{L}+u_{r}^{M} y_{r o}^{M}+u_{r}^{N} y_{r o}^{N}+u_{r}^{U} y_{r o}^{U}\right) \\
& \text { s.t. } \sum_{i=1}^{m}\left(v_{i}^{L} x_{i o}^{L}+v_{i}^{M} x_{i o}^{M}+v_{i}^{N} x_{i o}^{N}+v_{i}^{U} x_{i o}^{U}\right)=1 \\
& \sum_{r=1}^{s}\left(u_{r}^{L} y_{r j}^{L}+u_{r}^{M} y_{r j}^{M}+u_{r}^{N} y_{r j}^{N}+u_{r}^{U} y_{r j}^{U}\right) \\
& \quad-\sum_{i=1}^{m}\left(v_{i}^{L} x_{i j}^{L}+v_{i}^{M} x_{i j}^{M}+v_{i}^{N} x_{i j}^{N}+v_{i}^{U} x_{i j}^{U}\right) \geq 0, \quad j=1, \ldots, n \\
& u_{r}^{U} \geq u_{r}^{N} \geq u_{r}^{M} \geq u_{r}^{L} \geq 0, \quad r=1, \ldots, s \\
& v_{i}^{U} \geq v_{i}^{N} \geq v_{i}^{M} \geq v_{i}^{L} \geq 0, \quad i=1, \ldots, m
\end{aligned}
$$

As the model shows, if the optimal solution of the model (5) is equal to unity, that is $\theta_{o}^{\text {worst }}=1, D M U_{o}$ is called pessimistic inefficient; otherwise, it will be called pessimistic efficient. The interval efficiency for a fuzzy $D M U$ can be defined as $\left[\theta_{j}^{\text {worst }}, \theta_{j}^{\text {best }}\right]$. In order to measure the overall efficiency of the units, the geometric average $\left(\theta_{j}^{\text {geometric }}\right)$ can be defined as 


$$
\theta_{j}^{\text {geometric }}=\sqrt{\theta_{j}^{\text {best }} \theta_{j}^{\text {worst }}}, \quad j=1, \ldots, n
$$

The obtained $\theta_{j}^{\text {geometric }}$ can also be used for ranking and comparing the units.

\section{The proposed approach}

As mentioned before, the earlier fuzzy DEA research studies have ignored this important factor in their modelling. Not only does the proposed approach of the current paper emphasize the decision-maker views, but it also tends to bring out logical results. This is because such results can provide managers with reliable conditions to justify their future decisions in terms of resource consumptions and production. The alternative contribution of this proposed approach is generating a 95\% confidence interval for previous data sets, meaning that the probability assumption is utilized in such anticipations. Figure 1 shows the pattern of the proposed approach.

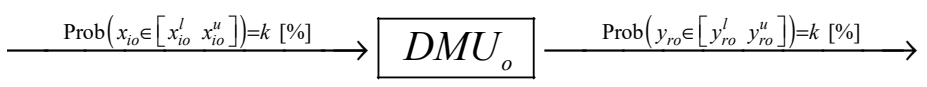

Fig. 1. The proposed pattern

As Figure 1 demonstrates, the $i$ th component of the input vector for $D M U_{o}$ meets the interval $\left[x_{i o}^{L}, x_{i o}^{U}\right]$ with the possibility of $K \%$. Similarly, the $r$ th component of the output vector is inserted in the interval $\left[y_{r o}^{L}, y_{r o}^{U}\right]$ with the $K \%$ possibility, meaning that with the possibility of $(1-K) \%$, the data will not be recorded in the interval. The significant difference in this pattern is its possibility axioms that are used for the uncertain fuzzy data set. In most cases, the confidence level $K$ is equal to $95 \%$. Based on the pattern in Fig. 1, the following model is applied for forecasting the interval efficiency while the confidence level is set at $95 \%$ :

$$
\begin{array}{ll}
\min & \theta_{o} \\
\text { s.t. } & \sum_{j=1}^{n} \lambda_{j} \bar{x}_{i j} \leq \theta \bar{x}_{i o}, \quad \forall i \\
& \operatorname{prob}\left(\bar{x}_{i j} \in I_{i j}\right)=K \%, \forall i, \forall j \\
& \sum_{j=1}^{n} \lambda_{j} \bar{y}_{r j} \leq \bar{y}_{r o}, \quad \forall r \\
& \operatorname{prob}\left(\bar{y}_{r j} \in I_{r j}\right)=K \%, \forall r, \forall j \\
& \lambda_{j} \geq 0, \quad \forall j
\end{array}
$$


In the above model, $I_{i j}=\left[\begin{array}{ll}x_{i j}^{l} & x_{i j}^{u}\end{array}\right]$ and $I_{r j}=\left[\begin{array}{ll}y_{r j}^{l} & y_{r j}^{u}\end{array}\right]$ are the $K \%$ confidence intervals of the inputs and outputs of $I_{i j}=\left[\begin{array}{ll}x_{i j}^{l} & x_{i j}^{u}\end{array}\right]$, respectively. By replacing $D M U_{j}$ and $I_{r j}=\left[\begin{array}{ll}y_{r j}^{l} & y_{r j}^{u}\end{array}\right]$, the model has the following format:

$$
\begin{aligned}
& \min \theta_{o} \\
\text { s.t. } & \sum_{j=1}^{n} \lambda_{j} \bar{x}_{i j} \leq \theta \bar{x}_{i o}, \quad \forall i \\
& \operatorname{prob}\left(\bar{x}_{i j} \in\left[\begin{array}{ll}
x_{i j}^{l} & x_{i j}^{u}
\end{array}\right]\right)=K \%, \forall i, \forall j \\
& \sum_{j=1}^{n} \lambda_{j} \bar{y}_{r j} \leq \bar{y}_{r o}, \quad \forall r \\
& \operatorname{prob}\left(\bar{y}_{r j} \in\left[\begin{array}{ll}
y_{r j}^{l} & y_{r j}^{u}
\end{array}\right]\right)=K \%, \forall r, \forall j \\
& \lambda_{j} \geq 0, \forall j
\end{aligned}
$$

As model (7) shows, the inputs and output vectors are inserted in an interval with the possibility of $K \%$. Model (7) is introduced for interval data. With the aim of the model (7), the suggested approach can be employed for fuzzy data sets (the objective of this paper). The main argument is emphasizing on previous data. That is, the data sets for $N$ th period are set in the confidence interval using the historical data of $N-1$ periods. Moreover, the historical data are employed to generate trapezoidal fuzzy data. With this end in view, an algorithm is proposed with four steps as follows.

\section{Confidence interval algorithm}

Step 1. Determine confidence interval $\alpha$ for $N$ th period by ITSM software with $N-1$ inputs and outputs of the previous period for $n D M U$ s. To reach a reliable outcome, $\alpha$ was set as $K \%$. As this step, the purpose is to forecast the future based on available data with the least possible error. Therefore, we remove the data flow, stabilize the variance with the aid of available transformations, identify the initial model, and finally forecast the $\alpha=K \%$ confidence interval for inputs and outputs.

Step 2. Impose management opinion on inputs and outputs concerning experience, expertise, familiarity with the workplace, performance, and history of units.

Step 3. Share confidence interval for inputs and outputs of step 1 with a confidence interval for step 2.

Step 4. Calculate mean $\bar{x}$ and standard deviation $\sigma$ of previous $N-1$ period of units. Then calculate $\bar{x} \pm 3 \sigma$ to convert the input and output to trapezoidal fuzzy data. 
The above algorithm provides a confidence interval for uncertain inputs or outputs with the confidence of $\alpha=K \%$. After this step, concerning these intervals, the next step deals with efficiency evaluation. In this step, an interval efficiency is considered. Therefore, applying the optimistic and pessimistic models can simplify the procedure. The proposed algorithm has four steps for forecasting efficiency. The steps are listed below.

\section{Efficiency and ranking algorithm}

Step 1. Use the optimistic and pessimistic models (3) and (5) to have an interval efficiency. The best and worst efficiencies are needed for the $N$ th period.

Step 2. Calculate the real efficiency of the $N$ th period. To validate the future period's efficiency and compare the calculated efficiency with real efficiency in the $N$ th period, the rank sum test is calculated as follows:

$$
T=\frac{\frac{s-m(m+n+1)}{2}}{\sqrt{\frac{m n(m+n+1)}{12}}}
$$

where $m$ denotes the number of first group efficiency scores or the efficiency with real data and $n$ denotes the number of second efficiency scores, that is, the scores of step 1 with available data from the previous algorithm (available fuzzy data). The statistic(s) approximately follows the normal distribution with a mean value of $m(m+n+1) / 2$ and variance of $m n(m+n+1) / 12$.

Step 3. If the model is validated, use the efficiency forecast for the $N+1$ period.

Step 4. Apply equation (6) for the ranking of units.

The proposed method looks simple to follow. As the algorithms show, the confidence intervals are generated. Moreover, future data sets can be inserted in an interval with $K \%$ confidence. This confidence allows the managers to focus on their production procedure. This way, the decision-makers are satisfied since their perspectives would lead to these desirable results. Based on these reliable results, the efficiency for $N$ th period is calculated. This outcome is trustable, and the production procedure can be justified with $K \%$ confidence. Furthermore, a validation test is done until the calculated efficiency is compared. Above all, the proposed algorithm lets ranking efficient units just with a simple geometric mean. In what follows, a numerical real case supports the proposed method of the current paper. 


\section{Numerical example}

To evaluate the applicability of the proposed algorithm, the automobile industry, as one of the main industries in Iran is selected. Identifying the determining and influential factors can affect the efficiency or inefficiency of this industry. Some of these factors include the conditions of the businesses, certain strategies, paying attention to research and development, the required liquidity and budget, and having a realistic vision according to the capabilities. Moreover, if there is no control and realistic vision about the future performance of this industry, the industry will face various challenges. Therefore, forecasting the future performance of this industry can play an important role in preventing loss and decreasing risks in financial and human resources. Thus, management can make a long-term plan for its performance and design plans for improving the management of the expenses and enhancement of efficiency.

As a practical example for the evaluation of the proposed model, 20 automobile industries were selected. The inputs and outputs were collected seasonally. They related to 50 time periods. The inputs were the number of personnel $\left(x_{1}\right)$ and number of equipment $\left(x_{2}\right)$. The outputs included value added $\left(y_{1}\right)$ and average employee productivity $\left(y_{2}\right)$. As the proposed confidence interval algorithm suggests, a four-step algorithm provides a confidence interval as follows:

Step 1. Inputs and outputs of previous 49 periods of these 20 industrial units along with $\alpha=95 \%$ were used to provide the inputs and outputs of the 50th period. The obtained confidence interval for inputs and outputs were inserted with the aid of the ITSM software. These steps were repeated for all inputs and outputs for 20 industrial units. For example, assume the first input of $D M U_{5}$. The initial data are shown in Table 1 and Fig. 2 as follows.

Table 1. The first input of $D M U_{5}$ for 49 periods of $20 D M U_{\mathrm{s}}$

\begin{tabular}{|c|c|c|c|c|c|c|c|c|c|}
\hline Step 1 & Step 2 & Step 3 & Step 4 & Step 5 & Step 6 & Step 7 & Step 8 & Step 9 & Step 10 \\
\hline 88.06 & 87.63 & 88.07 & 90.29 & 81.35 & 90.02 & 89.72 & 83.55 & 86.15 & 90.69 \\
\hline Step 11 & Step 12 & Step 13 & Step 14 & Step 15 & Step 16 & Step 17 & Step 18 & Step 19 & Step 20 \\
\hline 86.47 & 83.22 & 80.7 & 87.57 & 80.92 & 91.45 & 83.16 & 89.57 & 85.61 & 91.2 \\
\hline Step 21 & Step 22 & Step 23 & Step 24 & Step 25 & Step 26 & Step 27 & Step 28 & Step 29 & Step 30 \\
\hline 89.12 & 82.94 & 83.96 & 89.74 & 90.67 & 87.23 & 85.23 & 90.5 & 86.25 & 89.19 \\
\hline Step 31 & Step 32 & Step 33 & Step 34 & Step 35 & Step 36 & Step 37 & Step 38 & Step 39 & Step 40 \\
\hline 86.9 & 86.62 & 88.82 & 90.8 & 87.27 & 82.26 & 85.19 & 87.13 & 88.97 & 86.16 \\
\hline Step 41 & Step 42 & Step 43 & Step 44 & Step 45 & Step 46 & Step 47 & Step 48 & Step 49 & Step 50 \\
\hline 87.7 & 89.74 & 84.22 & 80.44 & 83.2 & 87.29 & 91.03 & 87.27 & 88.13 & 80.06 \\
\hline
\end{tabular}




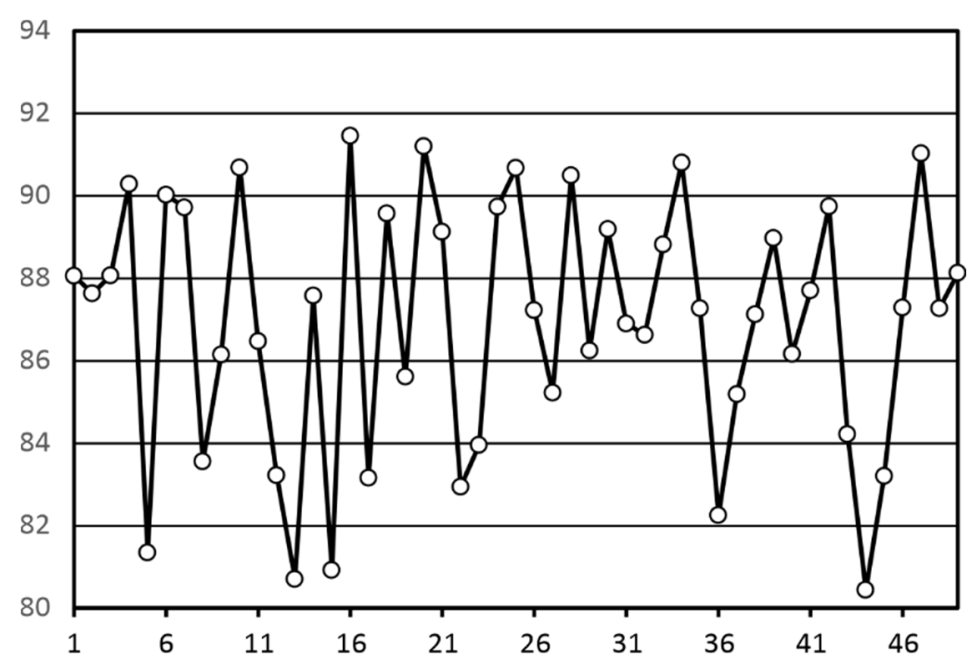

Fig. 2. Graphical representation of Table 1

By reducing the scattering and differentiation of the data for unit \#5, Fig. 3 is derived.

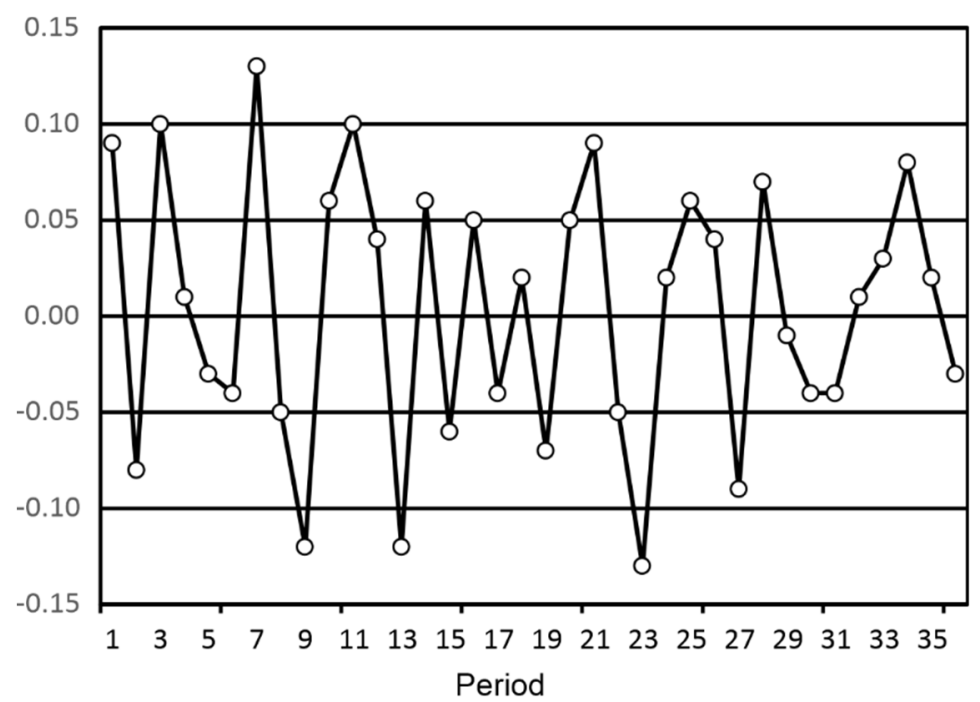

Fig. 3. Decreasing dispersion and differentiating in first input of $D M U_{5}$

Subsequently, the applied software makes data fit with an appropriate model to forecast inputs and outputs for the 50th period. After determining the appropriate model based on the available data, inputs and outputs were forecasted with the desirable possibility at a $95 \%$ confidence interval. Figure 4 shows the results. 


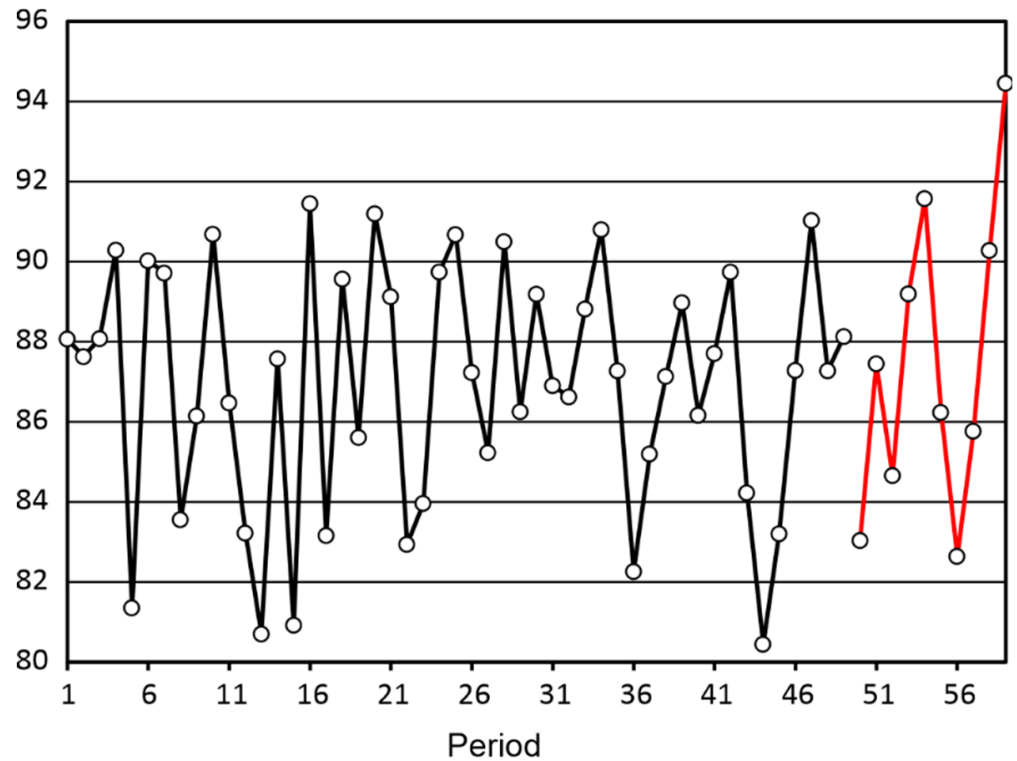

$-\infty$ The first input of DMU5

- F Forecasting 50th-59th periods for the first input of DMUs

Fig. 4. Forecasting 50th to 59th periods for the first input of $D M U_{5}$

Table 2 shows the related resulted of forecasting 95\% confidence interval for the inputs and outputs of the 50th-59th periods for the first input of $D M U_{5}$.

Table 2. Results of forecasting 50th-59th periods for the first input of $D M U$

\begin{tabular}{|c|c|c|c|}
\hline \multirow{2}{*}{ Step } & \multirow{2}{*}{ Prediction } & \multicolumn{2}{|c|}{ Approximate 95\% prediction bounds } \\
\cline { 3 - 4 } & & Lower & Upper \\
\hline 50 & 83.04 & 76.42 & 90.23 \\
\hline 51 & 87.45 & 79.85 & 95.78 \\
\hline 52 & 84.66 & 77.28 & 92.74 \\
\hline 53 & 89.20 & 80.91 & 98.33 \\
\hline 54 & 91.58 & 82.45 & 101.72 \\
\hline 55 & 86.24 & 77.09 & 96.47 \\
\hline 56 & 82.64 & 73.39 & 93.06 \\
\hline 57 & 85.77 & 75.68 & 97.19 \\
\hline 58 & 90.28 & 79.19 & 102.93 \\
\hline 59 & 94.46 & 82.39 & 108.92 \\
\hline
\end{tabular}

The first step of the confidence algorithm process is done for all units, and results are presented in Table 3 . 
Table 3. Forecasting the confidence interval of $95 \%$ of inputs and outputs

\begin{tabular}{|l|c|c|c|c|}
\hline$D M U_{i}$ & $I_{1}$ & $I_{2}$ & $O_{1}$ & $O_{2}$ \\
\hline$D M U_{1}$ & {$[76.4103 .55]$} & {$[60.2880 .70]$} & {$[37.4851 .00]$} & {$[47.6276 .63]$} \\
\hline$D M U_{2}$ & {$[78.1198 .89]$} & {$[57.6878 .23]$} & {$[40.5955 .28$} & {$[49.2880 .59]$} \\
\hline$D M U_{3}$ & {$[72.1788 .84]$} & {$[71.1392 .70]$} & {$[40.5955 .38]$} & {$[45.5664 .63]$} \\
\hline$D M U_{4}$ & {$[80.52103 .85]$} & {$[71.5799 .79]$} & {$[38.8252 .35]$} & {$[37.0055 .78]$} \\
\hline$D M U_{5}$ & {$[76.4290 .23]$} & {$[60.9086 .53]$} & {$[34.6846 .52]$} & {$[45.9365 .63]$} \\
\hline$D M U_{6}$ & {$[72.8895 .80]$} & {$[61.9581 .05]$} & {$[40.9562 .11]$} & {$[47.6469 .58]$} \\
\hline$D M U_{7}$ & {$[84.2498 .68]$} & {$[70.3492 .48]$} & {$[43.3855 .62]$} & {$[44.1668 .91]$} \\
\hline$D M U_{8}$ & {$[82.2198 .06]$} & {$[63.4195 .10]$} & {$[44.9061 .53]$} & {$[42.9565 .59]$} \\
\hline$D M U_{9}$ & {$[82.15101 .91]$} & {$[71.69105 .61]$} & {$[37.7453 .19]$} & {$[35.6457 .92]$} \\
\hline$D M U_{10}$ & {$[82.73101 .48]$} & {$[83.691121 .43]$} & {$[39.5951 .91]$} & {$[40.8563 .69]$} \\
\hline$D M U_{11}$ & {$[83.1999 .42]$} & {$[71.95102 .52]$} & {$[37.250 .98]$} & {$[31.4255 .29]$} \\
\hline$D M U_{12}$ & {$[75.4693 .44]$} & {$[69.3795 .91]$} & {$[39.7163 .52]$} & {$[38.9857 .01]$} \\
\hline$D M U_{13}$ & {$[72.1890 .48]$} & {$[71.3090 .09]$} & {$[43.0259 .88]$} & {$[50.8781 .03]$} \\
\hline$D M U_{14}$ & {$[76.5096 .92]$} & {$[57.6881 .76]$} & {$[27.9148 .83]$} & {$[44.5363 .99]$} \\
\hline$D M U_{15}$ & {$[79.88100 .39]$} & {$[61.4684 .79]$} & {$[38.6654 .05]$} & {$[45.3368 .69]$} \\
\hline$D M U_{16}$ & {$[75.9493 .02]$} & {$[57.7479 .56]$} & {$[40.5553 .98]$} & {$[50.5772 .96]$} \\
\hline$D M U_{17}$ & {$[74.6593 .15]$} & {$[73.7397 .53]$} & {$[32.8344 .94]$} & {$[46.8373 .92]$} \\
\hline$D M U_{18}$ & {$[74.3688 .89]$} & {$[66.8691 .21]$} & {$[39.3652 .45]$} & {$[47.9880 .81]$} \\
\hline$D M U_{19}$ & {$[83.12104 .39]$} & {$[64.1888 .25]$} & {$[40.8361 .70]$} & {$[40.3862 .24]$} \\
\hline$D M U_{20}$ & {$[74.9391 .92]$} & {$[61.8483 .21]$} & {$[40.3158 .21]$} & {$[43.1968 .37]$} \\
\hline
\end{tabular}

Coming to step 2 of the confidence interval algorithm and imposing management opinions on inputs and outputs, the obtained results are shown in Table 4.

Table 4. Inputs and outputs by applying management feedback

\begin{tabular}{|c|c|c|c|c|}
\hline$D M U_{i}$ & $I_{1}$ & $I_{2}$ & $O_{1}$ & $O_{2}$ \\
\hline$D M U_{1}$ & {$[72.3588 .42]$} & {$[78.2586 .48]$} & {$[45.6649 .47]$} & {$[48.9962 .35]$} \\
\hline$D M U_{2}$ & {$[78.3391 .95]$} & {$[75.9185 .59]$} & {$[38.3842 .40]$} & 43.8556 .95 \\
\hline$D M U_{3}$ & {$[77.5592 .87]$} & {$[77.8889 .60]$} & {$[40.4245 .58]$} & {$[44.9759 .61]$} \\
\hline$D M U_{4}$ & {$[78.5792 .23]$} & {$[74.6084 .12]$} & {$[42.2450 .58]$} & {$[42.7157 .77]$} \\
\hline$D M U_{5}$ & {$[79.3296 .94]$} & {$[74.4482 .04]$} & {$[41.7144 .27]$} & {$[45.2855 .34]$} \\
\hline$D M U_{6}$ & {$[77.5289 .18]$} & {$[75.9087 .32]$} & {$[41.8850 .16]$} & {$[42.7956 .71]$} \\
\hline$D M U_{7}$ & {$[78.0686 .20]$} & {$[65.7175 .59]$} & {$[41.9150 .19]$} & {$[49.3360 .29]$} \\
\hline$D M U_{8}$ & {$[83.2293 .84]$} & {$[63.4577 .55]$} & {$[47.2852 .24]$} & {$[49.6560 .67]$} \\
\hline$D M U_{9}$ & {$[84.0391 .03]$} & {$[74.2880 .46]$} & {$[38.7244 .54]$} & {$[51.0259 .88]$} \\
\hline$D M U_{10}$ & {$[78.0695 .40]$} & {$[70.8383 .13]$} & {$[41.3544 .79]$} & {$[49.7760 .81]$} \\
\hline$D M U_{11}$ & {$[80.6587 .37]$} & {$[64.4575 .65]$} & {$[44.9647 .74]$} & {$[45.0054 .98]$} \\
\hline$D M U_{12}$ & {$[78.8587 .15]$} & {$[69.0177 .81]$} & {$[44.2950 .95]$} & {$[53.2562 .51]$} \\
\hline$D M U_{13}$ & {$[79.6193 .45]$} & {$[74.8482 .75]$} & {$[42.8151 .27]$} & {$[51.0562 .39]$} \\
\hline$D M U_{14}$ & {$[83.2095 .72]$} & {$[76.3684 .38]$} & {$[42.4146 .65]$} & {$[43.0053 .62]$} \\
\hline$D M U_{15}$ & {$[73.3589 .65]$} & {$[75.3788 .47]$} & {$[39.9844 .18]$} & {$[48.7758 .41]$} \\
\hline
\end{tabular}


Table 4. Inputs and outputs by applying management feedback

\begin{tabular}{|c|c|c|c|c|}
\hline$D M U_{i}$ & $I_{1}$ & $I_{2}$ & $O_{1}$ & $O_{2}$ \\
\hline$D M U_{16}$ & {$[79.7591 .75]$} & {$[69.1976 .47]$} & {$[44.2046 .92]$} & {$[53.7463 .08]$} \\
\hline$D M U_{17}$ & {$[78.3686 .60]$} & {$[77.9087 .84]$} & {$[44.6351 .33]$} & {$[42.6750 .09]$} \\
\hline$D M U_{18}$ & {$[80.1692 .22]$} & {$[73.9981 .77]$} & {$[41.9151 .51]$} & {$[44.7353 .57]$} \\
\hline$D M U_{19}$ & {$[82.7091 .40]$} & {$[76.4082 .76]$} & {$[44.0748 .69]$} & {$[47.1159 .95]$} \\
\hline$D M U_{20}$ & {$[78.6088 .62]$} & {$[69.3075 .06]$} & {$[43.4250 .96]$} & {$[48.3159 .03]$} \\
\hline
\end{tabular}

In the following step (step 3), the confidence interval for inputs and outputs of step 1 is shared with a confidence interval of step 2 . The shared inputs and outputs of the 50th period are depicted in Table 5.

Table 5. 95\% confidence interval, inputs and outputs for the 50th period

\begin{tabular}{|c|c|c|c|c|}
\hline$D M U_{i}$ & $I_{1}$ & $I_{2}$ & $O_{1}$ & $O_{2}$ \\
\hline$D M U_{1}$ & {$[76.4888 .42]$} & {$[78.2580 .70]$} & {$[45.6649 .47]$} & {$[48.9962 .35]$} \\
\hline$D M U_{2}$ & {$[78.3391 .95]$} & {$[75.9178 .23]$} & {$[40.5942 .40]$} & {$[49.2856 .95]$} \\
\hline$D M U_{3}$ & {$[77.5588 .84]$} & {$[77.8889 .60]$} & {$[40.5945 .58]$} & {$[45.5659 .61]$} \\
\hline$D M U_{4}$ & {$[80.5292 .23]$} & {$[74.6084 .12]$} & {$[42.2450 .58]$} & 42.7155 .78 \\
\hline$D M U_{5}$ & {$[79.3290 .23]$} & {$[74.4482 .04]$} & {$[41.7144 .27]$} & {$[45.9355 .34]$} \\
\hline$D M U_{6}$ & {$[77.5289 .18]$} & {$[75.9081 .05]$} & {$[41.8850 .16]$} & {$[47.6456 .71]$} \\
\hline$D M U_{7}$ & {$[78.0686 .28]$} & {$[70.3475 .59]$} & {$[43.3850 .19]$} & {$[49.3360 .29]$} \\
\hline$D M U_{8}$ & {$[83.2293 .84]$} & {$[63.4577 .55]$} & {$[47.2752 .24]$} & {$[49.6560 .67]$} \\
\hline$D M U_{9}$ & {$[84.0391 .03]$} & {$[74.2880 .46]$} & {$[33.7244 .54]$} & {$[51.0257 .92]$} \\
\hline$D M U_{10}$ & {$[82.7395 .40]$} & {$[70.8383 .13]$} & {$[41.3544 .79]$} & {$[49.7760 .81]$} \\
\hline$D M U_{11}$ & {$[83.1987 .37]$} & {$[71.9575 .65]$} & {$[44.9647 .74]$} & {$[45.0054 .98]$} \\
\hline$D M U_{12}$ & {$[78.8587 .15]$} & {$[69.3777 .81]$} & {$[44.2950 .95]$} & {$[53.2557 .01]$} \\
\hline$D M U_{13}$ & {$[79.6190 .48]$} & {$[74.8782 .75]$} & {$[43.0251 .27]$} & {$[51.0162 .39]$} \\
\hline$D M U_{14}$ & {[] $83,2095.72$} & {$[76.3681 .76]$} & {$[42.4146 .65]$} & {$[44.5353 .62]$} \\
\hline$D M U_{15}$ & {$[79.8889 .65]$} & {$[75.3784 .79]$} & {$[39.9844 .18]$} & {$[48.7758 .41]$} \\
\hline$D M U_{16}$ & {$[79.7591 .75]$} & {$[69.1976 .47]$} & {$[44.2046 .92]$} & {$[53.7463 .08]$} \\
\hline$D M U_{17}$ & {$[78.3686 .60]$} & {$[77.9087 .84]$} & {$[44.6344 .94]$} & {$[46.8350 .09]$} \\
\hline$D M U_{18}$ & {$[80.1688 .89]$} & {$[73.9981 .77]$} & {$[41.9151 .21]$} & {$[47.9853 .57]$} \\
\hline$D M U_{19}$ & {$[83.1291 .40]$} & {$[76.4082 .76]$} & {$[44.0748 .69]$} & {$[47.1159 .95]$} \\
\hline$D M U_{20}$ & {$[78.6088 .62]$} & {$[69.3075 .06]$} & {$[43.4250 .96]$} & {$[48.3159 .03]$} \\
\hline
\end{tabular}

The last step in the first algorithm is converting the data set into trapezoidal fuzzy data. Calculating the mean $\bar{x}$ and standard deviation $\sigma$ of the previous 49 periods of units and utilizing $\bar{x} \pm 3 \sigma$ can convert the input and output to trapezoidal fuzzy data.

The vectors $x_{1}=\left(x_{1}^{L}, x_{1}^{M}, x_{1}^{N}, x_{1}^{U}\right), x_{2}=\left(x_{2}^{L}, x_{2}^{M}, x_{2}^{N}, x_{2}^{U}\right), y_{1}=\left(y_{1}^{L}, y_{1}^{M}, y_{1}^{N}, y_{1}^{U}\right)$ and $x_{1}^{M}$ and $x_{1}^{N}$ are fuzzy inputs and outputs. The components $y_{2}=\left(y_{2}^{L}, y_{2}^{M}, y_{2}^{N}, y_{2}^{U}\right)$ are the lower and upper bounds of the first inputs of $D M U$ s. As the third step of the confidence 
algorithm indicates, these values are sharing forecasted quantities for the 50th-period and possess the confidence interval including the managers' opinions.

Table 6. Fuzzy inputs and outputs

\begin{tabular}{|c|c|c|c|c|}
\hline$D M U_{j}$ & $x_{1}^{L}, x_{1}^{M}, x_{1}^{N}, x_{1}^{U}$ & $x_{2}^{L}, x_{2}^{M}, x_{2}^{N}, x_{2}^{U}$ & $y_{1}^{L}, y_{1}^{M}, y_{1}^{N}, y_{1}^{U}$ & $y_{2}^{L}, y_{2}^{M}, y_{2}^{N}, y_{2}^{U}$ \\
\hline$D M U_{1}$ & $\begin{array}{c}70.39,76.48 \\
88.42,94.51 \\
\end{array}$ & $\begin{array}{c}66.66,78,25 \\
80.70,92.28 \\
\end{array}$ & $\begin{array}{l}39.07,45.66 \\
49.47,56,05\end{array}$ & $\begin{array}{l}42.68,48.99 \\
62.33,68.66 \\
\end{array}$ \\
\hline$D M U_{2}$ & $\begin{array}{c}76.20,78.33 \\
91.95,94.08 \\
\end{array}$ & $\begin{array}{l}63.21,75.91, \\
78.23,90.93)\end{array}$ & $\begin{array}{c}(31.96,40.59, \\
42.40,51.04)\end{array}$ & $\begin{array}{l}39.40,49.28, \\
56.95,66.82)\end{array}$ \\
\hline$D M U_{3}$ & $\begin{array}{l}73.93,77.55, \\
88.84,92.47) \\
\end{array}$ & $\begin{array}{l}(72,19,77.88, \\
89.60,95.29) \\
\end{array}$ & $\begin{array}{r}35.58,40.59, \\
45.58,50.58) \\
\end{array}$ & $\begin{array}{l}(39.26,45.56, \\
59.61,65.90)\end{array}$ \\
\hline$D M U_{4}$ & $\begin{array}{l}(75.19,80.52 \\
92.23,97.57)\end{array}$ & $\begin{array}{l}(67.09,74.60 \\
84.12,91.63) \\
\end{array}$ & $\begin{array}{r}(38.61,42.24, \\
50.58,54.21) \\
\end{array}$ & $\begin{array}{l}(35.79,42.71, \\
55.78,62.25)\end{array}$ \\
\hline$D M U_{5}$ & $\begin{array}{l}(75.57,79.33 \\
90.23,93.99)\end{array}$ & $\begin{array}{c}(64.50,74.44 \\
82.04,91.98)\end{array}$ & $\begin{array}{l}(34.05,41.71, \\
44.27,51.93)\end{array}$ & $\begin{array}{l}(36.80,45.93, \\
55.34,64.46)\end{array}$ \\
\hline$D M U_{6}$ & $\begin{array}{l}(72.79,77.52, \\
89.18,93.91)\end{array}$ & $\begin{array}{c}(65.06,75.90 \\
81.05,91.88)\end{array}$ & $\begin{array}{c}36.57,41.88, \\
50.16,55.47)\end{array}$ & $\begin{array}{l}39.33,47.64, \\
56.71,65.01)\end{array}$ \\
\hline$D M U_{7}$ & $\begin{array}{l}70.71,78.06, \\
86.26,89.61)\end{array}$ & $\begin{array}{l}(61.53,70.34 \\
75.59,84.39)\end{array}$ & $\begin{array}{c}38.02,43.38, \\
50.19,55.54)\end{array}$ & $\begin{array}{r}(41.88,49.33 \\
60.29,67.74) \\
\end{array}$ \\
\hline$D M U_{8}$ & $\begin{array}{l}(77.49,83.22, \\
93.84,99.57) \\
\end{array}$ & $\begin{array}{l}(56.67,63.45 \\
77.55,84.33) \\
\end{array}$ & $\begin{array}{r}41.21,47.28, \\
52.24,58.31) \\
\end{array}$ & $\begin{array}{r}(43.07,49.65 \\
60.67,67.25) \\
\end{array}$ \\
\hline$D M U_{9}$ & $\begin{array}{c}(76.16,84.03 \\
91.03,98.9) \\
\end{array}$ & $\begin{array}{l}(63.81,74.28 \\
80.46,90.87) \\
\end{array}$ & $\begin{array}{r}(29.98,33.72, \\
44.54,48.28) \\
\end{array}$ & $\begin{array}{l}(41.78,51.02, \\
57.92,67.16)\end{array}$ \\
\hline$D M U_{10}$ & $\begin{array}{l}78.50,82.73, \\
95.40,99.62 \\
\end{array}$ & $\begin{array}{l}(62.43,70.83 \\
83.13,91.53) \\
\end{array}$ & $\begin{array}{r}(35.12,41.35, \\
44.79,51.02) \\
\end{array}$ & $\begin{array}{r}(41.97,49.77 \\
60.81,68.61) \\
\end{array}$ \\
\hline$D M U_{11}$ & $\begin{array}{l}75.68,83.19, \\
87.37,94.88) \\
\end{array}$ & $\begin{array}{l}59.37,71.95 \\
75,65,88.23) \\
\end{array}$ & $\begin{array}{r}37.50,44.96, \\
47.74,55.20) \\
\end{array}$ & $\begin{array}{l}(35.89,45.00, \\
54.98,64.09) \\
\end{array}$ \\
\hline$D M U_{12}$ & $\begin{array}{l}(72.74,78,85 \\
87.15,93.26) \\
\end{array}$ & $\begin{array}{l}(61.38,69.37 \\
77.81,85.80)\end{array}$ & $\begin{array}{c}(38.14,44.29, \\
50.95,57.10) \\
\end{array}$ & $\begin{array}{l}(42.89,53.25, \\
57.01,67.37) \\
\end{array}$ \\
\hline$D M U_{13}$ & $\begin{array}{l}(74.78,79.61, \\
90.48,95.30)\end{array}$ & $\begin{array}{l}(65.94,74.87 \\
82.75,91.68)\end{array}$ & $\begin{array}{c}(38.61,43.02, \\
51.27,55.67)\end{array}$ & $\begin{array}{r}(44.21,51.05 \\
62.39,69.23) \\
\end{array}$ \\
\hline$D M U_{14}$ & $\begin{array}{l}(78.42,83.20 \\
95.72,100.3)\end{array}$ & $\begin{array}{l}(66.16,76.36 \\
81.76,91.96)\end{array}$ & $\begin{array}{l}(34.69,42.41, \\
46.65,54.37)\end{array}$ & $\begin{array}{r}(35.69,44.53 \\
63.62,62.45) \\
\end{array}$ \\
\hline$D M U_{15}$ & $\begin{array}{l}(73.54,79.88 \\
89.65,95.98)\end{array}$ & $\begin{array}{l}(66.43,75.13 \\
84.79,93.73)\end{array}$ & $\begin{array}{r}(33.86,39.98, \\
44.18,50.30)\end{array}$ & $\begin{array}{l}(41.56,48.77 \\
58.41,65.62)\end{array}$ \\
\hline$D M U_{16}$ & $\begin{array}{l}(76.21,79.75 \\
91.75,95.29) \\
\end{array}$ & $\begin{array}{l}(58.79,69.19 \\
76.47,86.87) \\
\end{array}$ & $\begin{array}{r}(37.16,44.20 \\
46.92,53.96) \\
\end{array}$ & $\begin{array}{r}(48.85,53.74 \\
63.08,71.97) \\
\end{array}$ \\
\hline$D M U_{17}$ & $\begin{array}{l}(72.58,78.36 \\
86.69,92.38)\end{array}$ & $\begin{array}{l}(71.08,77.90 \\
87.84,94.66) \\
\end{array}$ & $\begin{array}{r}(35.30,44.63, \\
44.94,54.26) \\
\end{array}$ & $\begin{array}{l}(36.70,46.83, \\
50.09,60.22) \\
\end{array}$ \\
\hline$D M U_{18}$ & $\begin{array}{c}(72.40,80.16, \\
88.89,94.84) \\
\end{array}$ & $\begin{array}{l}(64.68,73.99 \\
81.77,91.08) \\
\end{array}$ & $\begin{array}{l}(37.80,41.91, \\
51.21,55.32)\end{array}$ & $\begin{array}{l}(36.58,49.98, \\
53.57,64.96) \\
\end{array}$ \\
\hline$D M U_{19}$ & $\begin{array}{l}(76.79,83.12, \\
91.40,97.73)\end{array}$ & $\begin{array}{l}(67.61,76.40 \\
82.76,91.55) \\
\end{array}$ & $\begin{array}{l}(38.16,44.07, \\
48.69,54.60) \\
\end{array}$ & $\begin{array}{l}(41.65,47.11, \\
59.95,65.41)\end{array}$ \\
\hline$D M U_{20}$ & $\begin{array}{l}(72.27,78.60 \\
88.62,94.95)\end{array}$ & $\begin{array}{l}(59.01,69.30 \\
75.06,85.35)\end{array}$ & $\begin{array}{l}(38.55,43.42, \\
50.96,55.83)\end{array}$ & $\begin{array}{l}(42.12,48.31, \\
59.03,65.22)\end{array}$ \\
\hline
\end{tabular}


The remaining two bounds, and $x_{1}^{L}$ and $\bar{x} \pm 3 \sigma, x_{1}^{U}$, are obtained by calculating $x_{1}^{U}$ holding it for all obtained y inputs and outputs. For example, in Table 4 , the first interval input for $D M U_{1}$ is $\left[\begin{array}{ll}76.48 & 88.42\end{array}\right]$. Calculating the quantities such as mean $\bar{x}=82.45$ and variance $\sigma=4.02$ for the previous 49 periods and imposing $\bar{x} \pm 3 \sigma$, the trapezoidal fuzzy interval for $D M U_{1}$ is obtained as $(70.39,76.48,88.42,94.51)$. Repeating the first algorithm for all previous 49 periods, the trapezoidal fuzzy data for 20 units will result. Equipped with these confidence data, with the confidence level $95 \%$ including the perspective of managers, we turn to the efficiency evaluation process whereby the second algorithm, efficiency evaluation algorithm, is now implemented to forecast the efficiency of $D M U$ s with available fuzzy data. By implementing step 1 of the proposed algorithm, the results are presented in Table 7.

Table 7. Efficiency of 50th period with fuzzy data and real data set

\begin{tabular}{|c|c|c|c|c|c|}
\hline$D M U_{j}$ & $\theta_{\text {TRFN-50 }}$ & $\theta_{\text {real-50 }}$ & $D M U_{j}$ & $\theta_{\text {TRFN-50 }}$ & $\theta_{\text {real-50 }}$ \\
\hline$D M U_{1}$ & 1 & 0.8847 & $D M U_{11}$ & 0.9638 & 0.9801 \\
\hline$D M U_{2}$ & 0.9401 & 0.9717 & $D M U_{12}$ & 1 & 0.9416 \\
\hline$D M U_{3}$ & 0.9587 & 0.9751 & $D M U_{13}$ & 0.9781 & 0.9932 \\
\hline$D M U_{4}$ & 0.9321 & 0.8828 & $D M U_{14}$ & 0.8920 & 0.8828 \\
\hline$D M U_{5}$ & 0.9148 & 1 & $D M U_{15}$ & 0.9626 & 1 \\
\hline$D M U_{6}$ & 0.9731 & 0.9431 & $D M U_{16}$ & 1 & 0.9291 \\
\hline$D M U_{7}$ & 1 & 0.9222 & $D M U_{17}$ & 0.9581 & 0.9615 \\
\hline$D M U_{8}$ & 1 & 1 & $D M U_{18}$ & 0.9687 & 0.9353 \\
\hline$D M U_{9}$ & 0.9188 & 1 & $D M U_{19}$ & 0.9247 & 1 \\
\hline$D M U_{10}$ & 0.9216 & 0.8143 & $D M U_{20}$ & 0.9957 & 0.9463 \\
\hline
\end{tabular}

As the first step in the second algorithm states, models (5) and (7) were introduced for efficiency evaluation. The first column of Table 7 shows the efficiency forecast for the 50th period $\left(\theta_{\mathrm{TRFN}-50}\right)$ employing the available trapezoidal data of Table 6 . The second column $\left(\theta_{\text {real-50 }}\right)$ forecasts the real efficiency for the 50th period. The following step of the algorithm, step 2, performs the rank-sum test to determine the validity of the method. In the rank-sum test equation, $m$ is the number of the first group $\left(\theta_{\text {real-50 }}\right)$, and $n$ denotes the number of the second group data $\left(\theta_{\text {TRFN }-50}\right)$. Also, the statistic $s$ approximately follows the normal distribution with the mean value of $m(m+n+1) / 2$ and variance of of $m n(m+n+1) / 12$. The result of the sum-rank test for available fuzzy data set in Table 6 is $T=0.528>-1.96$. This number suggests that there is not any statistically significant difference between the forecasted efficiency with models (5) and (7) and real efficiency of the 50th period. By conducting step 3, the efficiency of period $T=51$ is forecasted, and the results are presented in Table 8 . 
As Table 8 shows, the efficiency can be forecasted for the 51 st period with a confidence level of $95 \%$, employing the available trapezoidal fuzzy data set in Table 6 . The second column of Table 8 denotes the real efficiency scores of the 50th period. The forecasted efficiency scores indicate that units 5, 9, and 19 are listed as efficient units with the probability of $95 \%$ in the 51 st period. Moreover, unit \#13 preserves its efficiency score in the following period.

Table 8. Efficiency forecast of 51st period with fuzzy data

\begin{tabular}{|c|c|c|c|c|c|}
\hline$D M U_{j}$ & $\begin{array}{c}\text { Prediction } \\
\text { for the 51st } \\
\text { period }\end{array}$ & $\begin{array}{c}\text { Real efficiency } \\
\text { of the 50th } \\
\text { period }\end{array}$ & $D M U_{j}$ & $\begin{array}{c}\text { Prediction } \\
\text { for the 51st } \\
\text { period }\end{array}$ & $\begin{array}{c}\text { Real efficiency } \\
\text { of the 50th } \\
\text { period }\end{array}$ \\
\hline$D M U_{1}$ & 0.8067 & 0.8847 & $D M U_{11}$ & 1 & 0.9801 \\
\hline$D M U_{2}$ & 1 & 0.9717 & $D M U_{12}$ & 0.9267 & 0.9416 \\
\hline$D M U_{3}$ & 0.9714 & 0.9751 & $D M U_{13}$ & 0.8675 & 0.9932 \\
\hline$D M U_{4}$ & 0.7751 & 0.8828 & $D M U_{14}$ & 0.8910 & 0.8828 \\
\hline$D M U_{5}$ & 1 & 1 & $D M U_{15}$ & 0.9137 & 1 \\
\hline$D M U_{6}$ & 0.9269 & 0.9431 & $D M U_{16}$ & 0.8315 & 0.9291 \\
\hline$D M U_{7}$ & 0.8414 & 0.9222 & $D M U_{17}$ & 1 & 0.9615 \\
\hline$D M U_{8}$ & 0.9343 & 1 & $D M U_{18}$ & 0.9428 & 0.9353 \\
\hline$D M U_{9}$ & 0.9978 & 1 & $D M U_{19}$ & 1 & 1 \\
\hline$D M U_{10}$ & 0.8409 & 0.8143 & $D M U_{20}$ & 0.8912 & 0.9463 \\
\hline
\end{tabular}

As can be seen, the efficiency score of unit \#4 has been decreased about $10 \%$. The forecasted efficiency for the 51 st period is 0.7751 , but the real efficiency score in the previous period becomes 0.88 . The same situation holds true for unit \#13 whereby the quantity of the decrement gets close to $12 \%$. Executing step 4 makes a ranking for fuzzy $D M U$ s in the 51st period. With this end in view, models (5) and (7) are implemented; then the geometric mean is used to rank the forecasted fuzzy data in the 51st period. The results are presented in Table 9.

Three first columns of Table 9 represent the results of running models (5) and (7) and their geometric means. Column 4 illustrates the ranking of available fuzzy data sets for the 51st period. Unit \#11 has the first rank between 20 units with the confidence level of $95 \%$. In contrast, unit \#4 is placed in the last row with the same confidence. Apart from the ranking for the 51st period, the last column of Table 9 explains the ranking of available data sets applying the real efficiency scores of the previous period. Interestingly, unit \#19 has the first place in the 50th period, whilst unit \#11 is ranked as the first one in the next period. This unit is placed in the 7th row in the 50th period. Unit \#10 is placed in the last row in the 50th period. Unit \#4 still preserves the lowest place. Its place is degraded from 19 in the 50th period to 20 in the next period. $D M U_{2}, D M U_{10}$ and $D M U_{18}$, as well as $D M U_{11}$ experienced rank improvement. Admittedly, unit \#11 has been able to achieve the highest efficiency rank among the 20 units in the next period. 
Also, units $D M U_{8}, D M U_{13}$, and $D M U_{15}$ have been severely degraded in terms of their ranks. On the other hand, $D M U_{16}$ still ranked in the 15 th place. The reason behind this is lack of unit progress.

Table 9. Ranking of fuzzy units in 51st and in 50th periods

\begin{tabular}{|c|c|c|c|c|c|}
\hline \multirow[b]{2}{*}{$D M U_{j}$} & \multirow{2}{*}{$\begin{array}{c}\text { Optimistic } \\
\text { efficiency } \\
\theta_{51 \text { st }}^{\text {best }}\end{array}$} & \multirow{2}{*}{$\begin{array}{c}\text { Pessimistic } \\
\text { efficiency } \\
\theta_{51 \mathrm{st}}^{\text {worst }}\end{array}$} & \multirow{2}{*}{$\begin{array}{c}\text { Geometric average } \\
\text { efficiency } \\
\theta_{51 \mathrm{st}}^{\text {geom }}\end{array}$} & \multicolumn{2}{|c|}{ Ranking by } \\
\hline & & & & $\theta_{51 \mathrm{st}}^{\text {geom }}$ & $\theta_{50 \text { th }}^{\text {real }}$ \\
\hline$D M U_{1}$ & 0.8066 & 1 & 0.8981 & 19 & 17 \\
\hline$D M U_{2}$ & 1 & 1.0975 & 1.0476 & 3 & 9 \\
\hline$D M U_{3}$ & 0.9714 & 1.499 & 1.0416 & 4 & 8 \\
\hline$D M U_{4}$ & 0.7751 & 1 & 0.8803 & 20 & 19 \\
\hline$D M U_{5}$ & 1 & 1.0763 & 1.0374 & 5 & 1 \\
\hline$D M U_{6}$ & 0.9268 & 1.1136 & 0.9780 & 10 & 12 \\
\hline $\mathrm{DMU}_{7}$ & 0.8413 & 1 & 0.9172 & 13 & 16 \\
\hline$D M U_{8}$ & 0.9342 & 1.1232 & 0.9900 & 9 & 1 \\
\hline$D M U_{9}$ & 0.9977 & 1.1547 & 1.0720 & 2 & 1 \\
\hline$D M U_{10}$ & 0.8409 & 1 & 0.9170 & 14 & 20 \\
\hline$D M U_{11}$ & 1 & 1.2701 & 1.1269 & 1 & 7 \\
\hline$D M U_{12}$ & 0.9267 & 1.0567 & 0.9526 & 11 & 13 \\
\hline$D M U_{13}$ & 0.8674 & 1.1042 & 0.9114 & 16 & 6 \\
\hline$D M U_{14}$ & 0.8909 & 1.0264 & 0.9025 & 17 & 18 \\
\hline$D M U_{15}$ & 0.9137 & 1.0185 & 0.9221 & 12 & 1 \\
\hline$D M U_{16}$ & 0.8315 & 1 & 0.9118 & 15 & 15 \\
\hline$D M U_{17}$ & 0.9999 & 1.0733 & 0.0358 & 6 & 10 \\
\hline$D M U_{18}$ & 0.9428 & 1.1034 & 0.9903 & 8 & 14 \\
\hline$D M U_{19}$ & 1 & 1.0253 & 1.0125 & 7 & 1 \\
\hline$D M U_{20}$ & 0.8911 & 1.0256 & 0.9024 & 18 & 11 \\
\hline
\end{tabular}

Implementing these results, which were calculated with 95\% confidence level, will allow managers to trust the forecasted results and justify the production planning in this regard. Moreover, not only do the outcomes enforce the managers to investigate the causes of rank decrement, but they also create a chance for encouraging the units to achieve higher ranks in the coming periods. To sum up, the proposed algorithms enable the decision-makers to take the necessary measures for improving the efficiency in future periods and prevent reduction in productivity.

\section{Conclusions}

Data envelopment analysis (DEA) is a non-parametric technique for calculating the efficiency of $D M U$ s when both inputs and outputs are known and homogenous. Despite 
industrial managers' and decision-makers' interest in periodically forecasting the efficiency as means to regulate activities in terms of using resources and final output, the retrospective nature of standard DEA models prohibits this mission, which is a major drawback of these models. Assuming a 95\% confidence interval for input and output values, this paper aimed at addressing this significant drawback by inserting the managers' viewpoints, which is considered as one of the major strengths of the proposed algorithm. Putting the manager's view into account affords employing a fuzzy data set. Two algorithms were proposed in this regard. Firstly, a fuzzy data set was obtained for the next period employing the earlier data set supported with a confidence interval of $95 \%$. The second algorithm forecasted the efficiency measure for the next period and generated a procedure for ranking efficient units. A simple geometric mean simplified the ranking proses. To reveal the significance of difference between the real efficiency and forecasted quantities, the Rank Sum test was used in the algorithm steps. Finally, comparing the ranking places and efficiency values in two continuous periods offered a valuable chance for the manager to improve the performances and prevent any loss in resources and efficiency. A real numerical case exemplified and supported the idea behind the paper.

\section{References}

[1] Andersen P., Petersen N.C., A procedure for ranking efficient units in Data Envelopment Analysis, Manage. Sci., 1993, 39 (10), 1261-1264.

[2] BANKER R.D., CHARNES A., COOPER W.W., Some models for estimating technical and scale inefficiencies in data envelopment analysis, Manage. Sci., 1984, 30, 1078-1092.

[3] BARAK S., HeIDARY DAHOOEI J., A novel hybrid fuzzy DEA-Fuzzy MADM method for airlines safety evaluation, J. Air Trans. Manage., 2018, 73, 134-149.

[4] Charnes A., CoOPer W.W., Chance-constrained programming, Manage. Sci., 1959, 6, 73-79.

[5] Charnes A., CoOPer W.W., Programming with linear fractional functional, Naval Res. Log. Quart., 1962, 9, 181-186.

[6] Charnes A., CoOper W.W., Rhodes E., Measuring the efficiency of decision-making units, Eur. J. Oper. Res., 1978, 2, 429-444.

[7] Doyle J.R., Green R.H., Efficiency and cross-efficiency in DEA: Derivations, meanings and uses, J. Oper. Res. Soc., 1994, 45, 567-578.

[8] DOyLE J.R., GreEn R.H., Cross-evaluation in DEA: Improving discrimination among DMUs, INFOR, 1995, 33, 205-222.

[9] Emrouznejad A., Rostami-TABar B., Petridis K., A novel ranking procedure for forecasting approaches using data envelopment analysis, Techn. Forec. Soc. Change, 2016, 111, 235-243.

[10] FILDES R., WeI Y., ISMAIL S., Evaluating the forecasting performance of econometric models of air passenger traffic flows using multiple error measures, Int. J. Forec., 2011, 27, 902-922.

[11] Hatami-Marbini A., EmrouZnejad A., TAvana M., A taxonomy and review of the fuzzy EA literature: Two decades in the making, Eur. J. Oper. Res., 2011, 214 (3), 457-472.

[12] Hosseinzadeh Lotfi F., Navabakhs M., Tehranian A., Rostamy Malkhalifeh M., Shahverdi R., Ranking bank branches with interval data the application of DEA, Int. Math. Forum, 2007, 2 (9), 429-440. 
[13] Jahanshahloo G.R., Hosseinzadeh Lotfi F., Rostamy Malkhalifeh M., Ahadzadeh Namin M., A generalized model for data envelopment analysis with interval data, Appl. Math. Model., 2009, 33, 3237-3244.

[14] Kao C., LiU S.T., Fuzzy efficiency measures in data envelopment analysis, Fuzzy Sets Syst., 2000, 119, 149-160.

[15] Kwakernaak H., Fuzzy random variables. Part II. Algorithms and examples for the discrete case, Inf. Sci., 1979, 17 (3), 253-278.

[16] Kwakernaak H., Fuzzy random variables. Part I. Definitions and theorems, Inf. Sci., 1978, 15 (1), 1-29.

[17] Land K., Lovell C.A.K., Thore S., Chance-constrained data envelopment analysis, Manage. Dec. Econ., 1994, 14, 541-554.

[18] Lertworasirikul S., FAng S.C., Joines J.A., NutTle H.L.W., Fuzzy data envelopment analysis (DEA): A possibility approach, Fuzzy Sets Syst., 2003, 139, 379-394.

[19] Lim D., ANDERSON T.R., INMAN O., Choosing effective dates from multiple optima in technology forecasting using data envelopment analysis (TFDEA), Techn. Forec. Soc. Change, 2014, 88, 91-97.

[20] Lim D., ANDERSOn T.R., SHOTt T., Technological forecasting of supercomputer development: The march to exascale computing, Omega, 2015, 51, 128-135.

[21] Liang L., Wu J., CoOK W.D., Zhu J., Alternative secondary goals in DEA Cross Efficiency evaluation, Int. J. Prod. Econ., 2008, 113, 1025-1030.

[22] LiAng L., Wu J., CoOK W.D., Zhu J., The DEA game cross-efficiency model and its NASH equilibrium, Oper. Res., 2008, 56, 5, 1278-1288.

[23] Olesen O.B., Petersen N.C., Chance constrained efficiency evaluation, Manage. Sci., 1995, 41, $442-457$.

[24] Peykani P., Mohammadi E., Rostamy-Malkhalifeh M., Hosseinzadeh Lotfi F., Fuzzy data envelopment analysis approach for ranking of stocks with an application to Tehran Stock Exchange, Adv. Math. Fin. Appl., 2019, 4, 31-43.

[25] SAAti Mohtadi S., MEMARIANi A., JAhANShahloo G.R., Efficiency analysis and ranking of DMUs with fuzzy data, Fuzzy Opt. Dec., 2002, 1, 255-267.

[26] Sexton T.R., Silkman R.H., Hogan A.J., Data envelopment analysis: critique and extensions, New Dir. Progr. Eval., 1986, 32, 73-105.

[27] ShabanPour H., Yousefi S., FARZIPOOR SAEN R., Forecasting efficiency of green suppliers by dynamic data envelopment analysis and artificial neural networks, J. Cleaner, 2017, 142, 1098-1107.

[28] TAVASSOli M., FARZIPOOR SAEN R., Predicting group membership of sustainable suppliers via data envelopment analysis and discriminant analysis, Sust. Prod. Cons., 2019, 18, 41-52.

[29] Wang Y.M., ChIn K.S., Some alternative models for DEA cross-efficiency evaluation, Int. J. Prod. Econ., 2010, 128, 332-338.

[30] Wang Y.M., Chin K.S., Fuzzy data envelopment analysis: A fuzzy expected value approach, Exp. Syst. Appl., 2011, 37, 11678-11685.

[31] Xu B., OUENNICHE J., A data envelopment analysis-based framework for the relative performance evaluation of competing crude oil prices' volatility forecasting models, En. Econ., 2012, 34, 576-583.

[32] ZADEH L.A., Fuzzy sets, Inf. Control, 1965, 8, 338-358.

[33] ZADEH L.A., Fuzzy sets as a basis for a theory of possibility, Fuzzy Sets Syst., 1978, 1 (1), 3-28.

[34] Zerafat Angus L.M., TAJAddini A., Mustafa A., Jalal Kamali M., Ranking alternatives in a preferential voting system using fuzzy concepts and data envelopment analysis, Comp. Ind. Eng., 2012, $63,784-790$. 